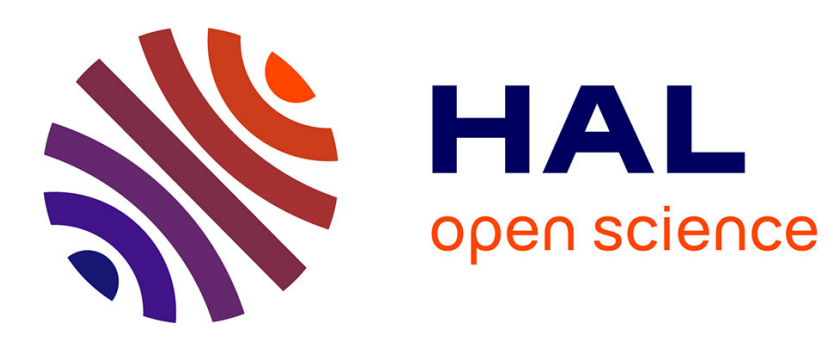

\title{
Rheo-mechanical and rheo-optical characterisation of ultra high molecular mass poly(methylmethacrylate) in solution
}

Ramiro Dell'Erba

\section{- To cite this version:}

Ramiro Dell'Erba. Rheo-mechanical and rheo-optical characterisation of ultra high molecular mass poly(methylmethacrylate) in solution. Polymers, 2000. hal-01998487

\section{HAL Id: hal-01998487 \\ https://hal.science/hal-01998487}

Submitted on 29 Jan 2019

HAL is a multi-disciplinary open access archive for the deposit and dissemination of scientific research documents, whether they are published or not. The documents may come from teaching and research institutions in France or abroad, or from public or private research centers.
L'archive ouverte pluridisciplinaire HAL, est destinée au dépôt et à la diffusion de documents scientifiques de niveau recherche, publiés ou non, émanant des établissements d'enseignement et de recherche français ou étrangers, des laboratoires publics ou privés. 


\section{ENEA}

Italian National Agency for New Technologies, Energy and Sustainable Economic Development

http://www.enea.it/en

http://robotica.casaccia.enea.it/index.php?lang=en

This paper is a pre-print. The final paper is available on:

Polymer "Rheo-mechanical and rheo-optical characterisation of ultra high molecular mass polymethyl(methacrilate) in solution", R. dell'Erba. Vol. 42/6, p.2655-2663 (2000). 


\title{
Rheo-mechanical and rheo-optical characterisation of ultra high molecular mass poly(methylmethacrylate) in solution
}

\author{
R. dell'Erba \\ Istituto di Ricerca e Tecnologia delle Materie Plastiche-National Council of Research (CNR), Via Toiano 6, 80072 Arco Felice Naples, Italy
}

\begin{abstract}
This paper presents rheo-mechanical and rheo-optical experimental characterisation of ultra-high molecular mass poly(methylmethacrylate) in solution. A set of ultra-high molecular mass (up to $2 \times 10^{7} \mathrm{~g} / \mathrm{mol}$ ) poly(methylmethacrylate), obtained in a previous work by B. Simionescu, was used together with a commercial set of lower molecular mass samples in order to cover two decades of molecular mass range. Two solvents were selected, toluene and $N, N$-dimethylformamide and the concentration was fixed at $2 \%$ (wt/wt). All the measurements were performed at $298^{\circ} \mathrm{K}$.

A complete rheo-mechanical characterisation, both in dynamic mode and in steady shear rate, was performed. In a second step, rheooptical techniques were able to measure the flow-induced birefringence, dichroism and the associated orientation angles. Using the experimental data obtained in this paper, we have derived the stress optical coefficients and shown that they are independent of shear rate and molar mass. We also explore the normal stress behaviour of the solutions tested. (C) 2000 Elsevier Science Ltd. All rights reserved.
\end{abstract}

Keywords: Poly(methylmethacrylate); Solution rheology; Molecular mass

\section{Introduction}

The rheological behaviour of a polymer in solution is of great interest in industrial polymer processing. The study of the viscoelastic behaviour of a polymer system at high shear rate and/or high molecular mass $\left(M_{\mathrm{w}}\right)$ is a very difficult task, owing to the strong elastic behaviour of the fluid. One of the possibilities to overcome these difficulties is to use the correspondence between molten polymer at low shear rate and ultrahigh molecular mass polymer in solution at high shear rate. To this aim, the study of the polymer in a large range of $M_{\mathrm{w}}$ is required. Also in this case there are great technical difficulties and, consequently, lack of experimental data on the behaviour of the solutions in the high shear rate range and/or high $M_{\mathrm{w}}$.

When high $M_{\mathrm{w}}$ are studied, generally, some new features may be measured because high $M_{\mathrm{w}}$ polymers are able to have a large chain extension and interactions between chains also at low concentrations and low shear rate.

Simionescu [1,2] has measured the first normal stress difference, $N_{1}$, vs. shear rate for poly(methylmethacrylate) (PMMA) of $M_{\mathrm{w}}$ at about $2 \times 10^{7} \mathrm{~g} / \mathrm{mol}$ in toluene at 2 and 6 $(\mathrm{wt} / \mathrm{wt})$ concentrations. He reported the presence of a three

E-mail address: dellerba@irtemp.na.cnr.it (R. dell’Erba). slope curve in the plot. To justify this behaviour, Cates, McLeisch and Marrucci [3] suggested to introduce a transverse dimension of polymer chain in the tube model, to overcome the unrealistic continuous decrease of shear stress with shear rate found in the Doi-Edwards model for entangled polymer. By this idea follows that three regions will occur in the plot of first normal stress difference vs. shear rate.

Unfortunately quite all the preceding literature was concerned with PMMA of $M_{\mathrm{w}}$ less than $3 \times 10^{6} \mathrm{~g} / \mathrm{mol}$ [413]. In 1955 Chinai $[4,5]$ et al. fitted the $\eta-M_{\mathrm{w}}$ relationships for a range of $M_{\mathrm{w}}$ between $0.4 \times 10^{6}$ and $3 \times 10^{6} \mathrm{~g} / \mathrm{mol}$ in toluene and other solvents. The $\eta-M_{\mathrm{w}}$ relationship, for low $M_{\mathrm{w}}$, was also investigated, in toluene, by Patroni [6] et al. (1965). In this last paper, the $M_{\mathrm{w}}$ range is between $2 \times 10^{3}$ and $7 \times 10^{3} \mathrm{~g} / \mathrm{mol}$ and the behaviour is theta solvent like owing to the low values of $M_{\mathrm{w}}$. In 1974 Graessley [7] investigated the flow properties of PMMA in diethyl-phthalate in a $M_{\mathrm{w}}$ range between $50 \times 10^{3}$ and $1.6 \times 10^{6} \mathrm{~g} / \mathrm{mol}$, finding results very similar to that found in the more investigated polystyrene in the same conditions. In recent times $[8,9]$ the Mark-Houwink constants for PMMA in tetrahydrofurane were investigated. The author has measured the MarkHouwink constants for ultra high molecular mass PMMA in toluene [14]. 
Table 1

Molecular mass $\left(M_{\mathrm{w}}\right)$, molecular mass distribution $\left(M_{\mathrm{w}} / M_{\mathrm{n}}\right)$ of the used polymer, and solvents

\begin{tabular}{lllll}
\hline No. & Polymer & $M_{\mathrm{w}}\left(10^{-6} \mathrm{~g} / \mathrm{mol}\right)$ & $\left(M_{\mathrm{w}} / M_{\mathrm{n}}\right)$ & Solvent \\
\hline 1 & PMMA $^{\mathrm{a}}$ & 0.14 & 1.13 & Toluene \\
2 & PMMA $^{\mathrm{a}}$ & 0.14 & 1.13 & DMF \\
3 & PMMA $^{\mathrm{a}}$ & 1.56 & 1.13 & Toluene \\
4 & PMMA $^{\mathrm{a}}$ & 1.56 & 1.13 & DMF \\
5 & PMMA $^{\mathrm{b}}$ & 10.5 & 1.30 & Toluene \\
6 & PMMA $^{\mathrm{b}}$ & 10.5 & 1.30 & DMF \\
7 & PMMA $^{\mathrm{b}}$ & 19.2 & 1.30 & Toluene \\
8 & PMMA $^{\mathrm{b}}$ & 19.2 & 1.30 & DMF \\
\hline
\end{tabular}

${ }^{\text {a }}$ Commercial sample as supplied by the company.

b Samples supplied by B.C. Simionescu. $M_{\mathrm{w}}$ measured by light scattering in different solvent (Ref. [17]).

This paper explores the rheo-optic behaviour of ultra high molecular mass PMMA in different solvents. Motivation for the work is to establish the experimental viability of rheooptic apparatus and also to determine rheo-optic parameters for the solutions tested. To do this two solvents were selected: toluene and $N, N$-dimethylformamide (DMF). The reason of this choice is that we would like to investigate the effect of a 'bad' solvent (DMF) and a 'good' solvent (toluene) on the rheo-logical behaviour of our solutions. The meaning of 'good' and 'bad' solvent must be searched in the Mark-Houwink exponent, $a$, of our systems, that gives a measurement of the interactions between the polymer chains and the solvent.

Two sets of rheological measurements were performed: a rheo-mechanical set and a rheo-optical one.

By rheo-mechanical devices we determined the materials functions of viscosity, storage and loss modulus at constant and variable strain and some other derived functions, i.e. the complex viscosity. The obtained results cover a six decades range in the values of viscosity.

A second set of measurements was based on rheo-optical investigation. This was done to prove whether it is possible or not to determine the flow-induced birefringence and dichroism, and to determine the orientation angle [15] of polymer aggregates.

The availability of a rheo-optical device allowed us to perform a local observation of the molecular interactions in polymer solutions; as a matter of fact rheo-mechanical characterisations are only able to perform an overall overview of the parameters, because they are dealing with average quantities on 'large' volume. Rheo-optical investigation allows an inside view of the mechanism of polymer interaction owing to the scale length involved in the experiment. Indeed in the optical investigations, by changing the wavelength used to investigate the sample, one can change the scattering function and, consequently, the objects involved in the scattering. Using rheo-optical techniques, therefore, we are able to detect information on local scale. The flowinduced anisotropy reflects as a change of index refractive tensor in which components can be measured and related to the constituents of the material [16]. The advantages of this method are the local scale investigation, the faster response time, the capability to isolate the actions of different objects.

Therefore the optical methods give complementary information to the classical mechanics used in Rheometry.

\section{Experimental}

\subsection{Materials}

Two kinds of PMMA samples have been used: two commercial samples, supplied by Latek, (Eppelheim, Germany) for the two lower $M_{\mathrm{w}}$, and two high $M_{\mathrm{w}}$ PMMA samples obtained by B. Simionescu using plasma-induced polymerisation in a previous work [17]. For the present study, therefore, four PMMA were selected, to cover a range of two decades $M_{\mathrm{w}}$. The molecular characteristics of the used material are shown in Table 1.

More information about the not commercial high $M_{\mathrm{w}}$ PMMA can be found in Ref. [17].

The solvents used were toluene and $N, N$-dimethylformamide (DMF). The solutions concentration was fixed at $2 \%$ (wt/wt).

\subsection{Techniques}

The solutions were prepared and stored in dark bottles kept under gently shackle and rotation for one week to be sure of a complete and homogeneous dissolution of the PMMA in the solvent. This time was determined by repeating some measurements on samples shackled for longer and shorter time.

In order to characterise the behaviour of the PMMA in solution the following rheo-logical techniques were used.

\subsubsection{Rheo-mechanical characterisation}

The measurements were carried out by a rotary rheo-meter by Physica (UDS200 model); the geometry used was a cone-plate geometry (radius $=3.75 \times 10^{-2} \mathrm{~m}$, angle $=$ $1.74 \times 10^{-2} \mathrm{rad}$, gap $\left.=50 \times 10^{-6} \mathrm{~m}\right)$, and the measurements were performed in strain control mode. The apparatus was equipped with a system to prevent solvent evaporation during the measurements, and thermostated at $298^{\circ} \mathrm{K}$. To this aim the cone-plate system was surrounded by a little cylindrical box. In the box there are two little tanks filled by the same solvent used to prepare the solution; hence the measurements were performed in a saturated solvent atmosphere, which render more difficult the evaporation of the solvent from the solutions. By this apparatus strain sweep, dynamic rate sweep, steady shear rate experiments were performed.

Strain sweep experiments were performed for the samples in the strain range 1-100 (\%) at a frequency $\omega$ of $40 \mathrm{rad} / \mathrm{sec}$. This was done in order to check that the storage modulus, $G^{\prime}$, and the loss modulus, $G^{\prime \prime}$ are not function of the strain, in our range of parameters, as required from the linear viscoelastic theory. 


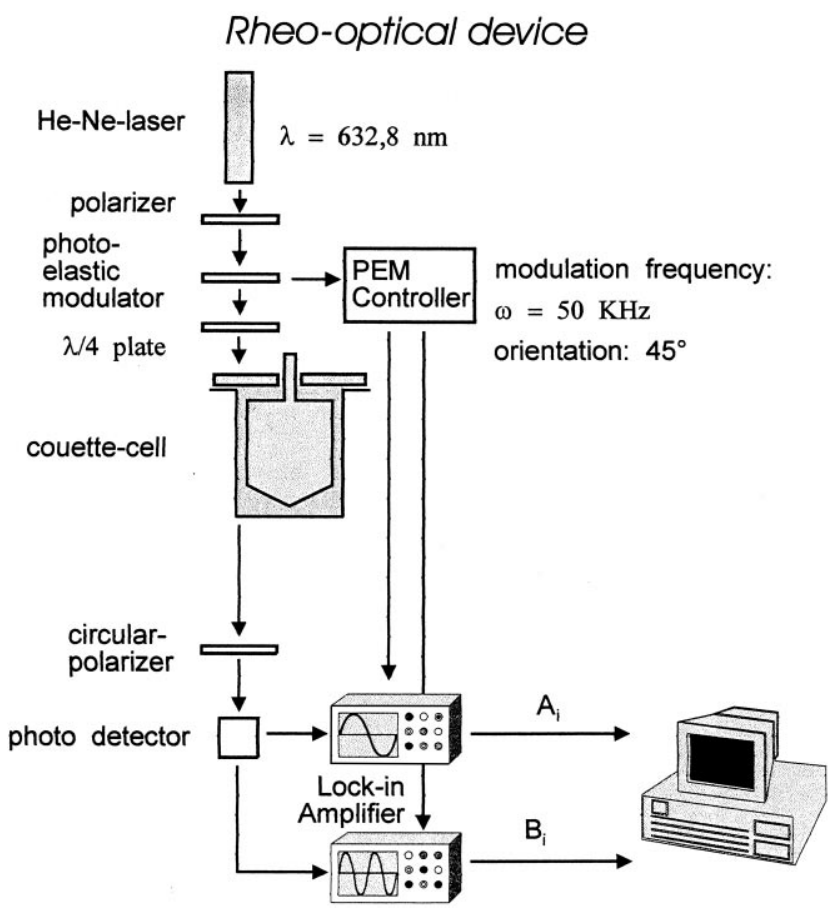

Fig. 1. Schematic diagram of the rheo-optical device, in birefringence measurements configuration.

Dynamic oscillation experiments were performed, to obtain the storage modulus $G^{\prime}$, the loss modulus $G^{\prime \prime}$ and, consequently, the complex viscosity $\eta^{*}=\left(\mathrm{G}^{\prime 2}+\mathrm{G}^{\prime \prime 2}\right)^{1 / 2} / \omega$, all of them as function of the frequency $\omega$. The experiments were led at a fixed sample strain of $20 \%$ amplitude.

To obtain the viscosity, $\eta$, versus the shear rate, all the samples were undertaken to a steady state shear rate experiment. A sufficient delay was waited to allow the samples to reach a true steady state; the continue collection of the torque on paper is indicative of the status of the sample to understand if the time delay has been sufficient.

\subsubsection{Rheo-optical characterisation}

In our samples, we started from a supposed isotropic solution and the anisotropy was induced, by flow, owing to the orientation of the polymer segments. The principal connection between rheooptical and rheological experiments is give by the stress optical rule, which states that the refractive index tensor, $\mathbf{n}$, is connected with the stress tensor, $\tau$, by a linear relationship:

$\mathbf{n}-n_{\mathrm{m}} \mathbf{I}=C(\tau+p \mathbf{I})$

where $n_{\mathrm{m}}$ is the mean refractive index, $\tau$ the stress tensor, $p$ the idrostatic pressure and I the identity tensor. $C$ is called the stress optical coefficient. To the tensor $\mathbf{n}$ are associated three eigenvalues which characterise three eigendirections (principal axis of the tensor). The different values of the eigenvalues are linked to the different velocities of light propagation.

If the material is isotropic there is no preferred direction so that the velocity of light is the same whatever is the propagation direction of the wave. On the contrary, if the material is anisotropic the propagation velocity depends on the propagation direction.

From a mathematical point of view, if $\mathbf{n}$ is the refractive index tensor and in the case of isotropic solutions its eingenvalues are triple degenerated; flow induced anisotropy reduced the degree of degeneracy. In particular we choose a flow able to reduce the degeneracy to two equal eigenvalues double degenerated and one eigenvalue not degenerated; to this last belongs only one eigenvector and the difference between the eingenvalues is called birefringence. The angle between the not degenerate eigenvector and the axes of the laser is called orientation angle $\theta$. The complex part of $\mathbf{n}$ is linked to dichroism.

The rheo-optical measurements were performed in a home-made apparatus [15] able to determine the flow birefringence $\Delta n^{\prime}$ and the orientation angle as a function of the shear rate $\gamma$; in the same experiment moreover, in a second experiment, the flow dichroism $\Delta n^{\prime \prime}$ and the extintion angle $\chi$ can be determined. Both birefringence and dichroism are generated into the sample by a steady shear flow. A scheme of the apparatus is showed in Fig. 1. The operating laser wavelength was $\lambda=0.6328 \times 10^{-6} \mathrm{~m}$, and the polarisation vector was rotating, by a photoelastic modulator (PEM) at frequency of $50 \mathrm{kHz}$. The modulate laser beam passes the sample, posed in double slit cell $2.44 \times 10^{-2} \mathrm{~m}$ long, the beam is normal to the shear plane of flow and the intensity of the light was collected by a photodiode.

By the photodiode, we collect an integrated value of the intensity of the light, which crossed the sample. In particular we get an analogyc signal of the form:

$I=\left(I_{0} \sin 2(\theta-\alpha)\right) \sin 2 \delta^{\prime} / 2$

where $I_{0}$ is the intensity of incident light, $\alpha$ the polarisation angle value, $\delta^{\prime}$ the phase shift, linked to the birefringence value, and $\theta$ is the orientation angle. From this equation, it is clear that a single intensity measurement will not allow one to know both $\theta$ and $\delta^{\prime}$. Thus we have changed the value of the polarisation angle $\alpha$ to obtain as two different measurements that can be combined together to calculate $\theta$ and $\delta^{\prime}$.

A very sensible system, based on two lock-in amplifiers, is needed to extract a very little amplitude periodic signal with a large noise signal in background and to be able to convert the signal in the values of birefringence and dichroism.

A complete description of the experimental apparatus is reported in Ref. [15].

\section{Results}

\subsection{Rheo-mechanical measurements}

The linear theory of viscoelasticity requires that the material functions storage and loss modulus, $G^{\prime}$ and $G^{\prime \prime}$, must be independent by the strain. A sweep strain experiment was 


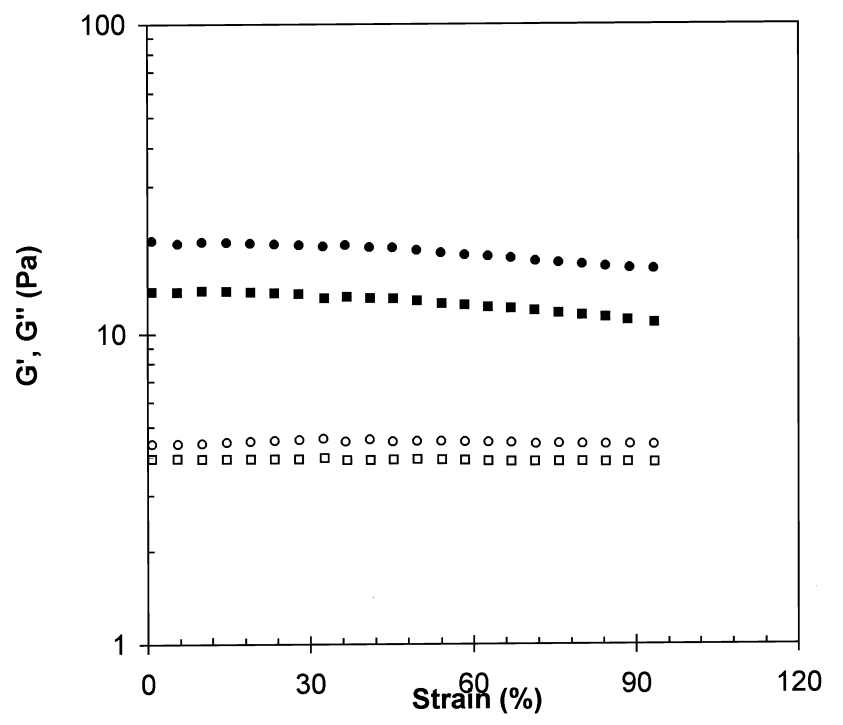

Fig. 2. The storage modulus $G^{\prime}$ (filled symbols), the loss modulus $G^{\prime \prime}$ (open symbols), as function of the $\%$ amplitude $A$, for PMMA in toluene (square symbols) and DMF (circle symbols) at $\omega=40 \mathrm{rad} / \mathrm{sec} . M_{\mathrm{w}}=$ $1.92 \times 10^{7} \mathrm{~g} / \mathrm{mol}$.

performed at the fixed frequency of $40 \mathrm{rad} / \mathrm{sec}$ for the highest $M_{\mathrm{w}}$ sample in order to be sure to work in the validity range of the theory also in the most difficult case. In Fig. 2 the results, i.e. $G^{\prime}$ and $G^{\prime \prime}$ vs strain (\%), in toluene and DMF, are shown respectively. It can be pointed out that also for the highest $M_{\mathrm{w}} G^{\prime}$ and $G^{\prime \prime}$ are practically independent of the strain. High elasticity behaviour, resolving in high $G^{\prime}$ values, can be recognised for both the solutions, particularly for the DMF solutions. Other measurements, performed at different $\omega$ gave the same results.

The storage and the loss modulus $G^{\prime}$ and $G^{\prime \prime}$, recorded at $20 \%$ of the strain, versus the oscillation frequency, $\omega$, are shown in Fig. 3a-3b for toluene and DMF solutions respectively; both the functions increase with increasing the $M_{\mathrm{w}}$. The crossing point between $G^{\prime}$ and $G^{\prime \prime}$ is shifted toward low frequency with increasing $M_{\mathrm{w}}$, indicating as the elastic behaviour is increased with increasing the $M_{\mathrm{w}}$.

The linear trends of the low $M_{\mathrm{w}}$ samples show a slope of 2 and 1 , for $G^{\prime}$ and $G^{\prime \prime}$ respectively according to the Newtonian behaviour of these samples in the shear rate range examined. The same experiments were repeated at $40 \%$ strain, for these samples, obtaining results that could be perfectly overlapped to the Fig. 3a-3b.

The behaviour of the viscosity, $\eta$, for the PMMA samples in toluene and DMF versus shear rate is shown in Fig. $4 \mathrm{a}$ and $4 \mathrm{~b}$ respectively. It should be noted the large extension of the $\eta$ in the plots; indeed six decades for $\eta$ are covered. The trends of the complex viscosity $\eta^{*}=\left(G^{12}+G^{1 / 2}\right)^{1 / 2} / \omega$, obtained by dynamic measurements, are overlapped to the trends of viscosity to show the validity of the Cox-Merz rule for our samples in our range of parameters [18].

From the trends of the flow curves we can distinguish a Newtonian region, where the stress has a linear dependency
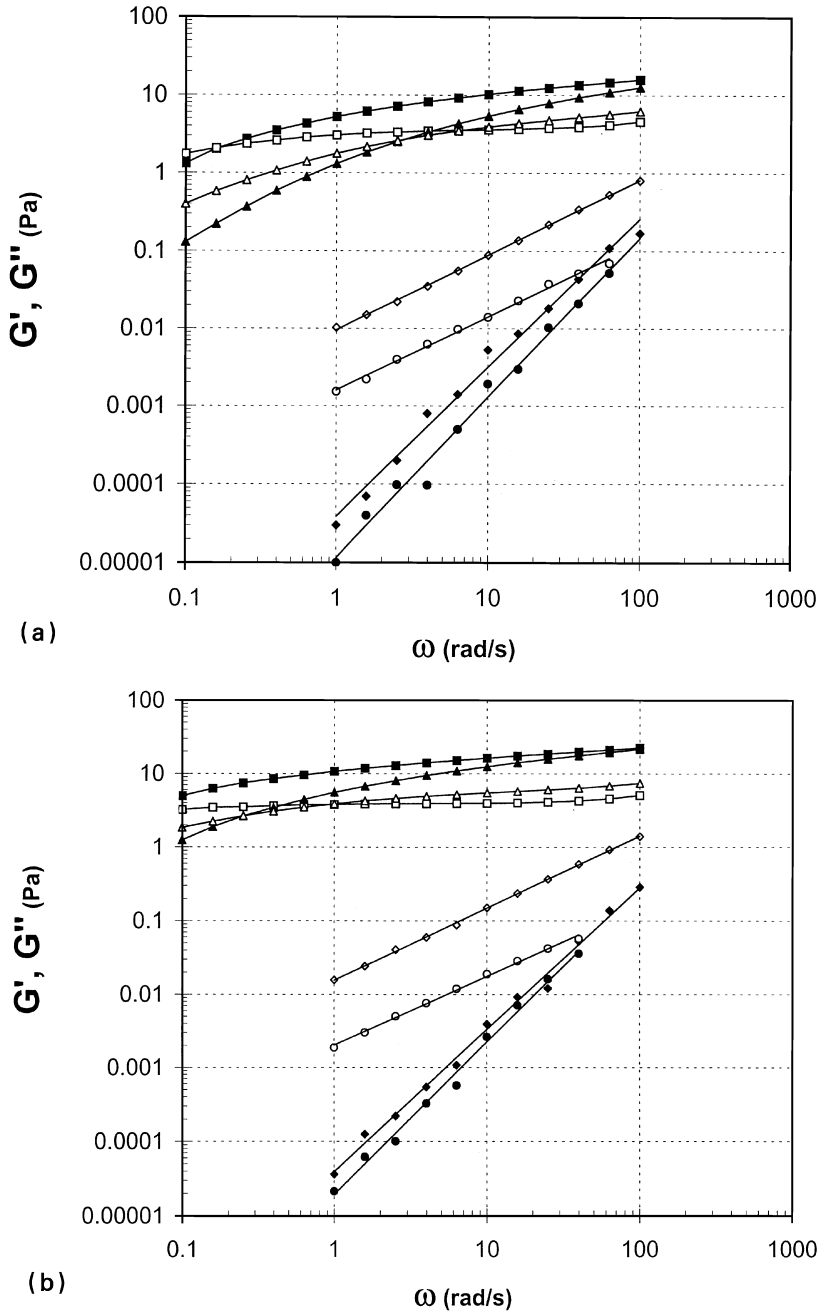

Fig. 3. (a) The storage modulus $G^{\prime}$ (filled symbols), the loss modulus $G^{\prime \prime}$ (open symbols), as function of the frequency $\omega$, for PMMA in toluene with different molar mass at $20 \%$ strain. $\square$ and $\square$ for $M_{\mathrm{w}}=1.92 \times 10^{7} \mathrm{~g} / \mathrm{mol}$. $\Delta$ and $\Delta$ for $M_{\mathrm{w}}=1.06 \times 10^{7} \mathrm{~g} / \mathrm{mol} . \diamond$ and $\diamond$ for $M_{\mathrm{w}}=0.15 \times 10^{7} \mathrm{~g} / \mathrm{mol}$. and $\bigcirc$ for $M_{\mathrm{w}}=0.014 \times 10^{7} \mathrm{~g} / \mathrm{mol}$. (b) The storage modulus $G^{\prime}$ (filled symbols), the loss modulus $G^{\prime \prime}$ (open symbols), as function of the frequency $\omega$, for PMMA in DMF with different molar mass at $20 \%$ strain. $\square$ and $\square$ for $M_{\mathrm{w}}=1.92 \times 10^{7} \mathrm{~g} / \mathrm{mol} . \Delta$ and $\triangle$ for $M_{\mathrm{w}}=1.06 \times 10^{7} \mathrm{~g} / \mathrm{mol} . \diamond$ and $\diamond$ for $M_{\mathrm{w}}=0.15 \times 10^{7} \mathrm{~g} / \mathrm{mol}$. $\bullet$ and $\bigcirc$ for $M_{\mathrm{w}}=0.014 \times 10^{7} \mathrm{~g} / \mathrm{mol}$.

from the shear rate, and a non-Newtonian region. The slope of non-Newtonian region was found $-0.74 \pm$ $0.01\left(\mathrm{~Pa} \times \mathrm{s}^{2}\right)$ for toluene based solutions and $-0.65 \pm 0.01\left(\mathrm{~Pa} \times \mathrm{s}^{2}\right)$ for DMF based solution; therefore in our semidilute state solution the viscosity is depending on the solvent quality. Grassley [19] has derived, in case of concentrated solutions, the theoretical value of the slope of $-0.82\left(\mathrm{~Pa} \times \mathrm{s}^{2}\right)$, but under the hypothesis of homogeneous solutions on the scale of segment density. When the segment density is not uniform a pronounced concentration dependency of the slope in the non linear region of the flow curve has been observed experimentally $[20,21]$.

In a bad solvent the interaction between the polymer chains is favourite with respect of the solvent, leading to a less homogeneous distribution of the segments density; this 

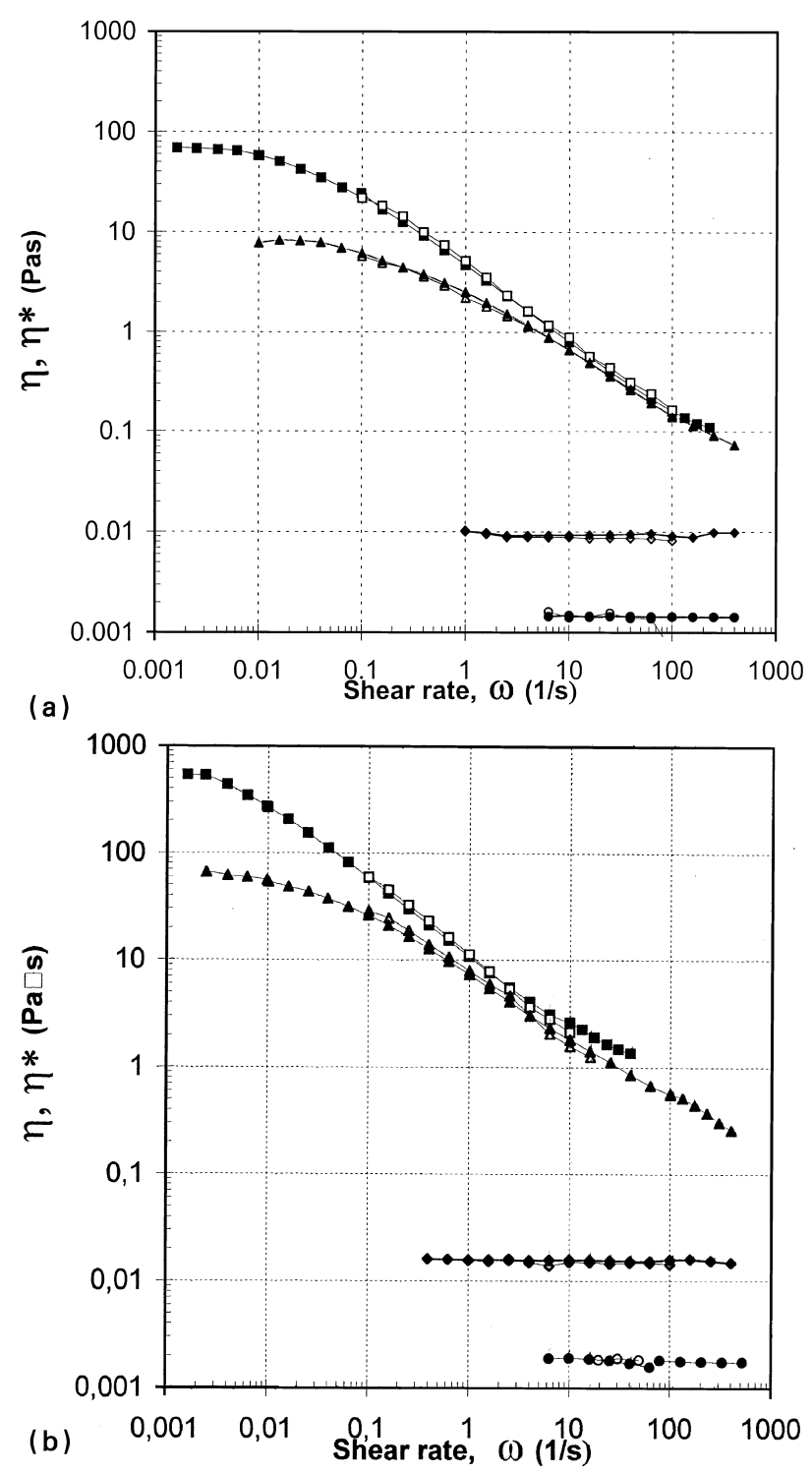

Fig. 4. (a) The viscosity $\eta$ (filled symbols), together with the complex viscosity $\eta^{*}$ (hollow symbols), as function of shear rate and frequency $\omega$, for PMMA in toluene with different molar mass. $\square$ and $\square$ for $M_{\mathrm{w}}=$ $1.92 \times 10^{7} \mathrm{~g} / \mathrm{mol}$. $\Delta$ and $\Delta$ for $M_{\mathrm{w}}=1.06 \times 10^{7} \mathrm{~g} / \mathrm{mol}$. $\diamond$ and $\diamond$ for $M_{\mathrm{w}}=$ $0.15 \times 10^{7} \mathrm{~g} / \mathrm{mol}$. $\bigcirc$ and $\bigcirc$ for $M_{\mathrm{w}}=0.014 \times 10^{7} \mathrm{~g} / \mathrm{mol}$. (b) The viscosity $\eta$ (filled symbols), together with the complex viscosity $\eta^{*}$ (hollow symbols), as function of shear rate and frequency $\omega$, for PMMA in DMF with different molar mass.. $\square$ and $\square$ for $M_{\mathrm{w}}=1.92 \times 10^{7} \mathrm{~g} / \mathrm{mol}$. $\Delta$ and $\triangle$ for $M_{\mathrm{w}}=1.06 \times 10^{7} \mathrm{~g} / \mathrm{mol} . \diamond$ and $\diamond$ for $M_{\mathrm{w}}=0.15 \times 10^{7} \mathrm{~g} / \mathrm{mol} . \bullet$ and $\bigcirc$ for $M_{\mathrm{w}}=0.014 \times 10^{7} \mathrm{~g} / \mathrm{mol}$.

could explain the lower slope values found for DMF solutions (see Fig. 4b).

A qualitative explanation can be pointed out if we take in account that in a good solvent the polymer coils are less sensitive to the presence of the other coils with respects to a poor solvent based solution, owing to a stronger interaction between the molecular chains and the solvent. By this reason the independence of the viscosity from the $M_{\mathrm{w}}$ is reached at higher shear rate with respect to toluene based samples, consequentially at fixed shear rate, a higher shear stress is observed in samples with higher molecular mass.

The viscosity increases with increasing $M_{\mathrm{w}}$, by keeping the shear rate and the other parameters fixed, but it becomes independent from it at high shear rate in the non-Newtonian region.

The DMF solutions show a higher value of viscosity, keeping all the other parameters fixed, but this difference seems to disappear as the molar mass is increased. They also show a higher elastic behaviour with respect of toluene based solutions, which represents a serious problem in the measurements of the rheo-mechanical parameters. In fact this pronounced elastic behaviour is responsible for strong flow instabilities, as observed by Kulicke [22] for polystyrene in solution. This flow instabilities lead to stop the measurements, and they are generated especially in higher molar mass samples in DMF solutions.

The used shear rates were found not sufficient to start degradation phenomena [20,23-25], according to the literature. Moreover to be sure that our samples have no suffered mechanical degradation some measurements were repeated on many samples, after being waited its relaxation time. The little differences measured are not significant and they are inside the experimental errors.

\subsection{Rheo-optical measurements}

To perform measurements of flow-induced birefringence each sample was subjected to 'flow reversal experiments'. Therefore the flow was started, kept at fixed a shear rate, for a certain time, stopped and restarted in the opposite direction.

The values of $\Delta n^{\prime}$ and $\theta$, were detected by the apparatus [15], showed in Fig. 1. Unfortunately it has been not possible to collect any rheo-optical data by the solutions of the lower molar masses (samples 1-4), owing to their low optical activity.

In Fig. $5 \mathrm{a}-5 \mathrm{~b}$ the orientation angle $\theta$ of PMMA vs. the shear rate, in toluene and DMF are shown respectively. It can be outlined as the coils are more oriented as the molar mass is increased. At a shear rate of $100 \mathrm{~s}^{-1}$ quite all the coils of the PMMA samples are fully oriented. A qualitative explanation can be carried out assuming the validity of the stress optical rule and observing that the slope of the stress versus shear rate is increase with increase $M_{\mathrm{w}}$.

In fig. $6 \mathrm{a}-6 \mathrm{~b}$ the values of birefringence $\Delta n^{\prime}$ for PMMA versus shear rate in toluene and DMF are shown respectively. From these plots the following conclusion can be carried out:

The values of $\Delta n^{\prime}$ increases with increasing shear rate, at fixed $M_{\mathrm{w}}$.

The values of $\Delta n^{\prime}$ increases with increasing $M_{\mathrm{w}}$, at fixed the shear rate.

Comparing samples of PMMA with the same $M_{\mathrm{w}}$ but solved in the two different solvents we can note as the $\Delta n^{\prime}$ values are higher for DMF based solutions and $\theta$ lower, with 


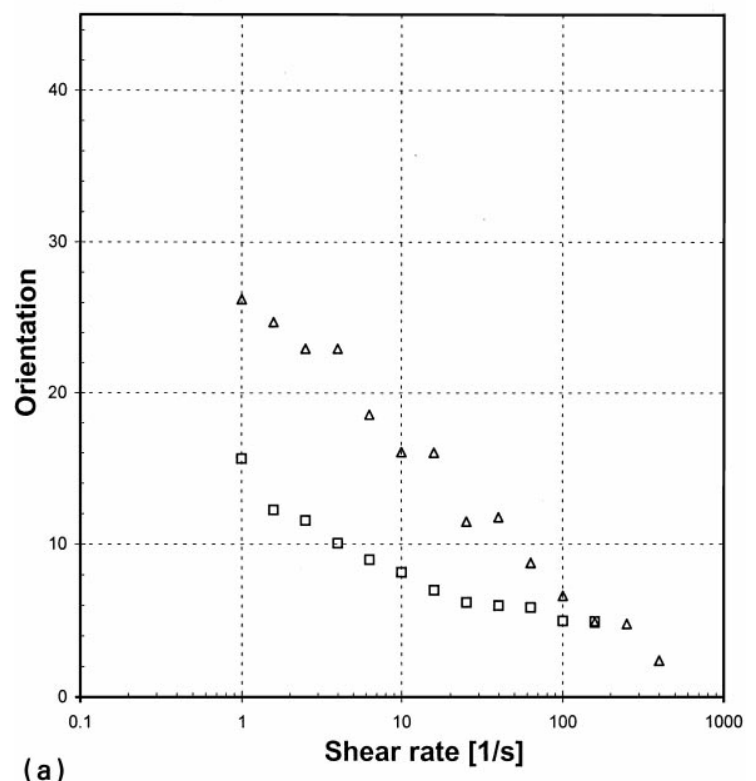

(a)

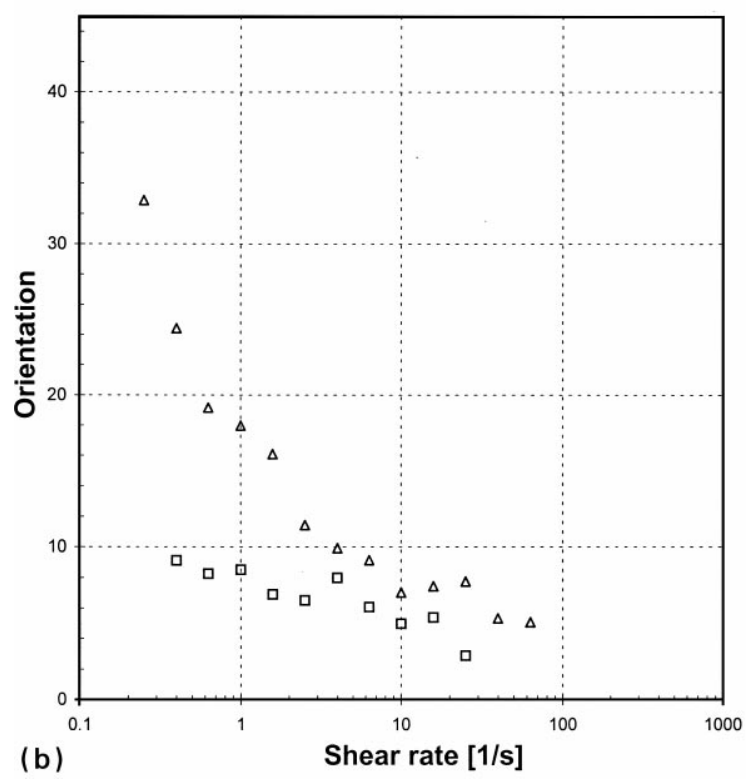

Fig. 5. (a) The orientation angle $\theta$ as function of shear rate for PMMA in toluene, with different molar mass. $\square$ for $M_{\mathrm{w}}=1.92 \times 10^{7} \mathrm{~g} / \mathrm{mol} . \Delta$ for $M_{\mathrm{w}}=1.06 \times 10^{7} \mathrm{~g} / \mathrm{mol}$. (b) The orientation angle $\theta$ as function of shear rate for PMMA in DMF, with different molar mass. $\square$ for $M_{\mathrm{w}}=1.92 \times$ $10^{7} \mathrm{~g} / \mathrm{mol} . \triangle$ for $M_{\mathrm{w}}=1.06 \times 10^{7} \mathrm{~g} / \mathrm{mol}$.

respect to toluene based solutions; this finding can be briefly explained by two reasons:

(a) A higher stress support by DMF solutions kept constant the shear rate and the molar mass. (Cfr. Figs. $4 a-4 b)$.

(b) A different stress optical coefficient $\mathrm{C}$, as expected from the literature.

It should be noted that as the magnitude of birefringence is very little also at high shear rate, lying in the range values between $10^{-9}$ and $10^{-7}$.

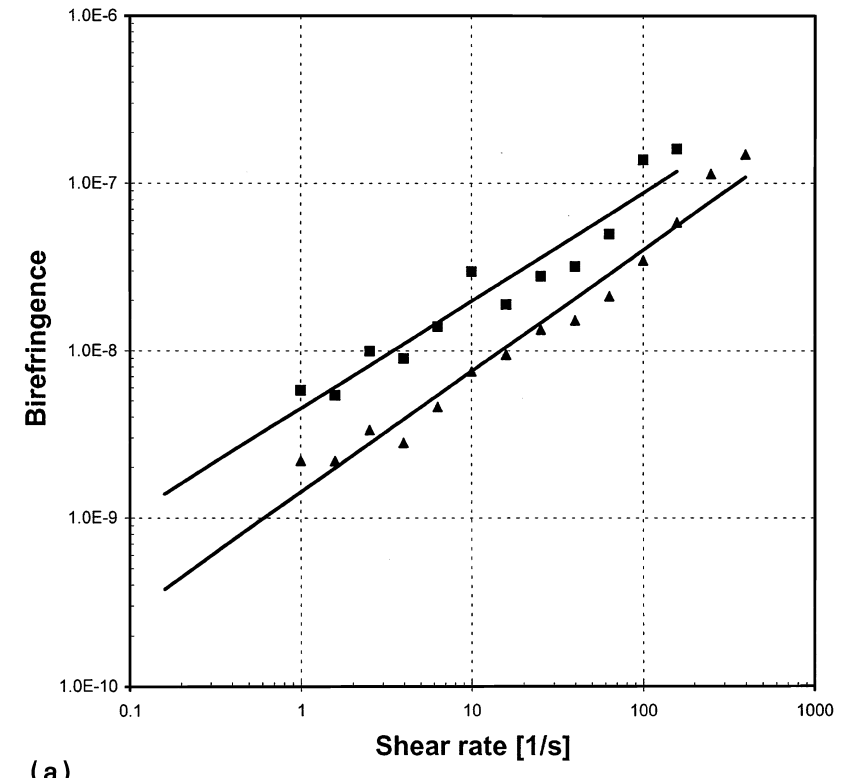

(a)

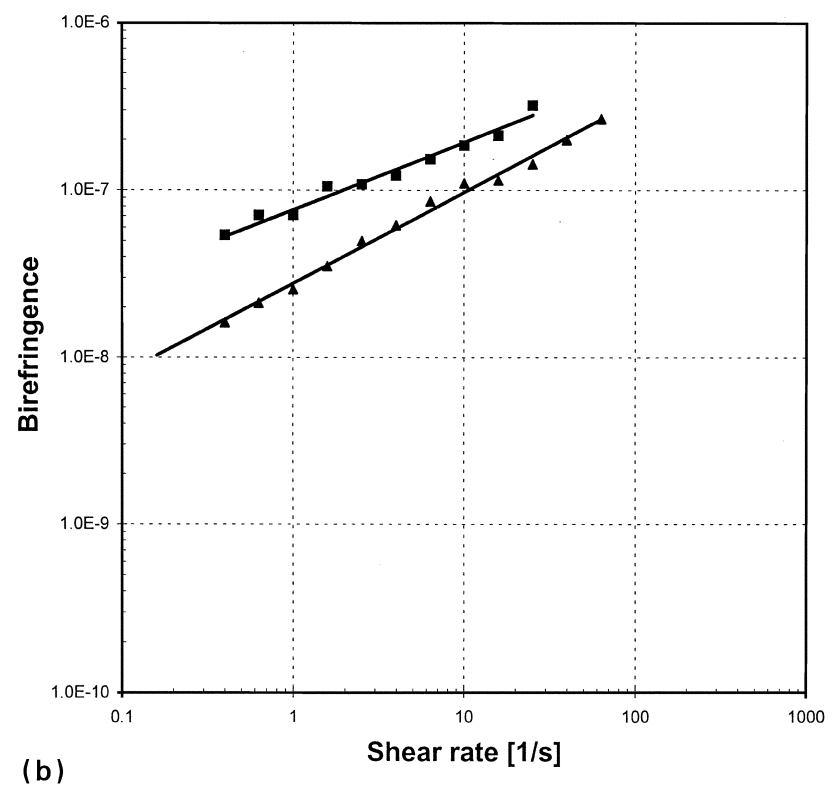

Fig. 6. (a) The birefringence $\Delta n^{\prime}$ as function of shear rate for PMMA in toluene, with different molar mass. $M_{\mathrm{w}}=1.92 \times 10^{7} \mathrm{~g} / \mathrm{mol}$. $\Delta$ for $M_{\mathrm{w}}=$ $1.06 \times 10^{7} \mathrm{~g} / \mathrm{mol}$. (b) The birefringence $\Delta n^{\prime}$ as function of shear rate for PMMA in toluene, with different molar mass. for $M_{\mathrm{w}}=1.92 \times$ $10^{7} \mathrm{~g} / \mathrm{mol}$. $\Delta$ for $M_{\mathrm{w}}=1.06 \times 10^{7} \mathrm{~g} / \mathrm{mol}$.

By these measurements, together with the shear stress measured by rheo-mechanical devices, we can calculate the stress optical coefficient (SOC) and the first normal stress difference $\left(N_{1}=\sigma_{11}-\sigma_{22}\right)$. In Fig. $7 \mathrm{a}-7 \mathrm{~b}$ the SOC vs. shear rate is plotted for PMMA in toluene and DMF. The values of SOC show non dependence on shear rate and molecular mass which is consistent with the literature of other polymer solutions. From Fig. $7 \mathrm{a}-7 \mathrm{~b}$ we can note as the SOC for DMF based solutions is higher than in toluene; the order of magnitude of the SOC is ten times higher than in toluene and their 

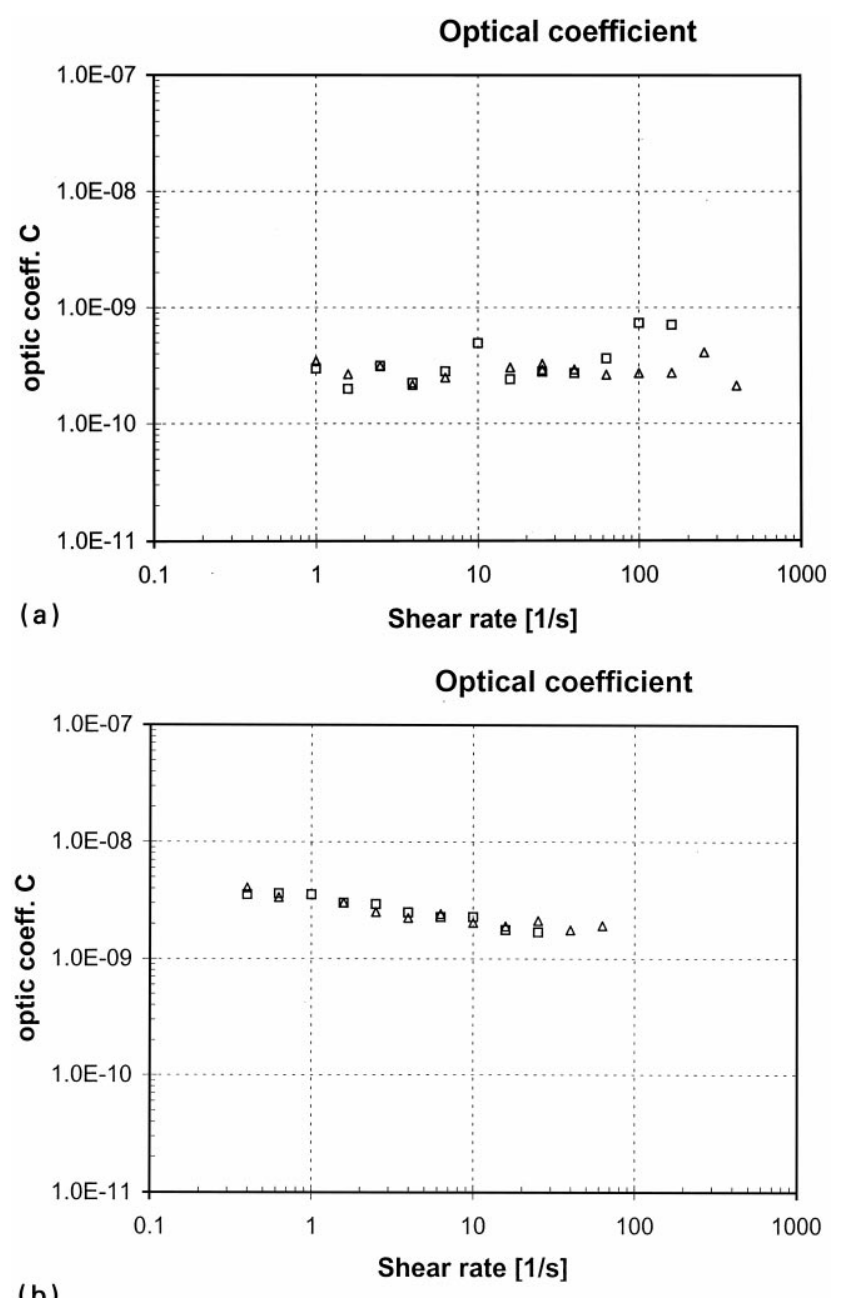

(b)

Fig. 7. (a) The stress optical coefficient, as function of shear rate for PMMA in toluene, with different molar mass. $\square$ for $M_{\mathrm{w}}=1.92 \times 10^{7} \mathrm{~g} / \mathrm{mol} \Delta$ for $M_{\mathrm{w}}=1.06 \times 10^{7} \mathrm{~g} / \mathrm{mol}$. (b) The stress optical coefficient, as function of shear rate for PMMA in DMF, with different molar mass. $\square$ for $M_{\mathrm{w}}=$ $1.92 \times 10^{7} \mathrm{~g} / \mathrm{mol} . \triangle$ for $M_{\mathrm{w}}=1.06 \times 10^{7} \mathrm{~g} / \mathrm{mol}$.

values are $2.8 \times 10^{-9} \pm 0.4 \times 10^{-9}$ and $2.9 \times 10^{-10} \pm$ $0.3 \times 10^{-9}$, respectively.

Using now the stress optical rule we are able to derive the first normal stress difference. In Fig. $8 \mathrm{a}-8 \mathrm{~b}$ the first normal stress difference $N_{1}$ vs. shear rate, in toluene and DMF respectively, are shown.

To perform a quantitative comparison between the linear model and the three slopes model used to describe the Gauss coefficient as a hypothesis test was calculated [26]. The Gauss coefficient is defined by the expression:

$G=\frac{1}{N-m} \sum_{i=1}^{N}\left(\alpha_{i}-\bar{\alpha}_{i}\right)^{2}$,

i.e. the measure of 'error estimation' residuals between the experimental data, $\alpha_{i}$, and the numerical models $\bar{\alpha}_{i} . N$ is the number of experimental points and $\mathrm{m}$ is the number of parameters employed in the model to fit the data. $m$ is
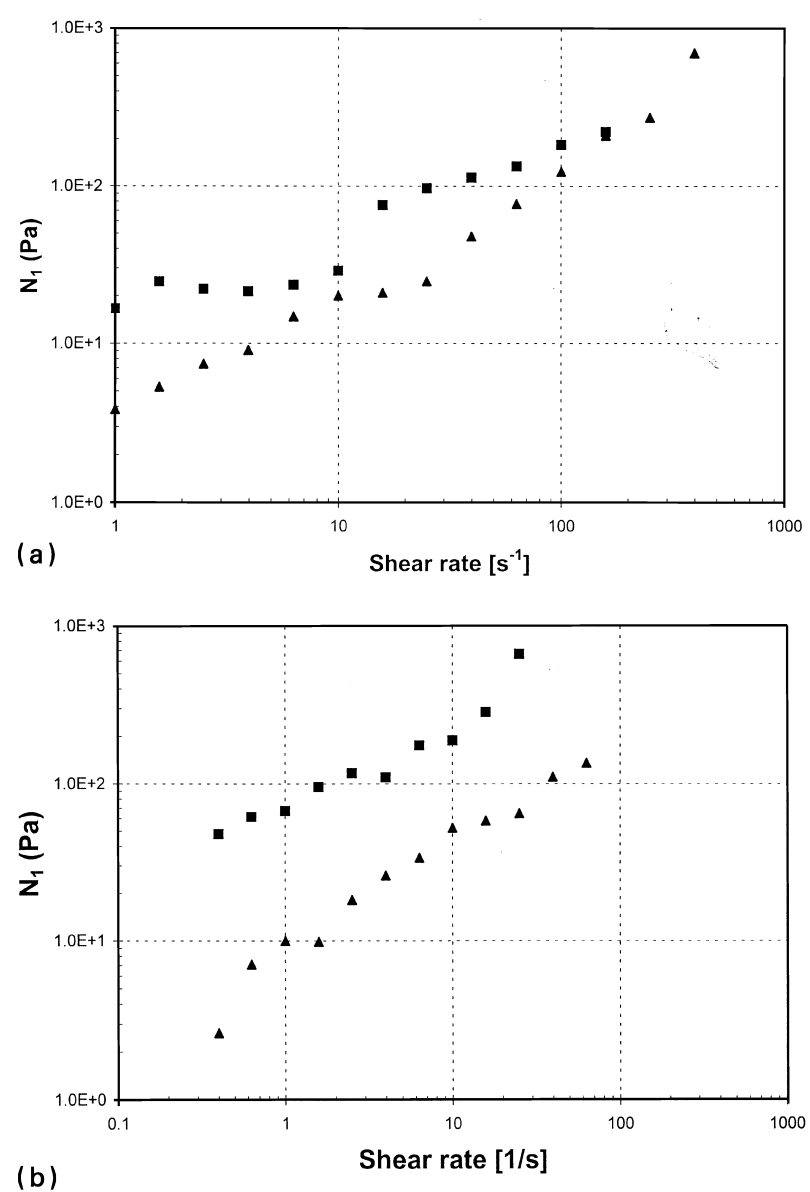

Fig. 8. (a) The first normal stress difference $N_{1}$ for PMMA in toluene with different molar mass. $\quad M_{\mathrm{w}}=1.92 \times 10^{7} \mathrm{~g} / \mathrm{mol}$. $\Delta$ for $M_{\mathrm{w}}=$ $1.06 \times 10^{7} \mathrm{~g} / \mathrm{mol}$. (b) The first normal stress difference $N_{1}$ for PMMA in DMF with different molar mass. $\square$ for $M_{\mathrm{w}}=1.92 \times 10^{7} \mathrm{~g} / \mathrm{mol}$. $\boldsymbol{\Delta}$ for $M_{\mathrm{w}}=1.06 \times 10^{7} \mathrm{~g} / \mathrm{mol}$.

equal to 2 in the case of the simple linear model and 6 $(=2 \times 3)$ for the three slopes model. The found coefficients are shown in Table 2 for the linear and three slopes model, respectively.

These findings mean that in spite of its lower complexity, the linear method fit the experimental data significantly better than the other model. In fact, by definition, the Gauss hypothesis test was born to compare different methods taking in account the degree of freedom, i.e. the number of parameters to be fitted in the model.

Therefore, a three-slope behaviour of PMMA in solution observed in Simionesu's paper cannot be supported only by these data.

After the birefringence investigation, some experiments were performed with the aim to detect dichroism. No difference in the signal can be detected between the shear zone and the non-shear zone, indicating the absence of flow induced dichroism in any of our solutions. This result outlines absences of aggregates, able to adsorb lights, and confirm the homogeneity of our solutions on this scale. 
Table 2

Gauss coefficients relative to the single linear model and the three slope model

\begin{tabular}{|c|c|c|c|c|}
\hline No. & $\begin{array}{l}M_{\mathrm{w}} \\
\left(10^{-6} \mathrm{~g} / \mathrm{mol}\right)\end{array}$ & Solvent & $\begin{array}{l}\text { Gauss coefficient } \\
\text { (Linear model) }\end{array}$ & $\begin{array}{l}\text { Gauss coefficient } \\
\text { (Three slopes model) }\end{array}$ \\
\hline 1 & 0.14 & Toluene & - & - \\
\hline 2 & 0.14 & DMF & - & - \\
\hline 3 & 1.56 & Toluene & - & - \\
\hline 4 & 1.56 & DMF & - & - \\
\hline 5 & 10.5 & Toluene & 0.08 & 0.12 \\
\hline 6 & 10.5 & DMF & 0.05 & 0.09 \\
\hline 7 & 19.2 & Toluene & 0.20 & 0.25 \\
\hline 8 & 19.2 & DMF & 0.06 & 0.11 \\
\hline
\end{tabular}

\section{Conclusions}

This paper has produced new rheological data using ultrahigh molecular mass polymer PMMA, not available as commercial sample, dissolved in toluene and DMF. A complete set of samples, covering a large range of molecular weight (from $0.01 \times 10^{7}$ up to $2 \times 10^{7} \mathrm{~g} / \mathrm{mol}$ ) and six decades of viscosity values has been characterised using both rheo-mechanical and rheo-optical techniques. This represents new work for PMMA samples owing to the low optical activity of PMMA in solutions. Using ultra high molecular mass PMMA we produced, for the first time, data on the birefringence of PMMA in toluene and DMF.

The measurements have been used to calculate the stress optical coefficient and the first normal stress difference by the stress optical rule. Because of the chosen concentration ( $2 \% \mathrm{wt} / \mathrm{wt}$ ) our solutions can be classified in the semi-dilute state solutions, hence we found a strong dependency from the solvent in the non-Newtonian region as expected from the literature. The solutions showed a high elastic behaviour, particularly in the DMF based solutions.

The rheo-mechanical analysis has showed as the high $M_{\mathrm{w}}$ samples have a non-Newtonian behaviour also at very low shear rate and the Cox-Merz rule was found valid for our systems.

The rheo-optical analysis has showed the birefringence values are low (about $10^{-9}$ ), but their behaviour is similar to some other well known system like polystyrene in toluene. The stress optical coefficient was found higher in DMF solutions with respect to toluene solutions.

Simionescu [1,2] et al. have found a three-slope behaviour plotting the first normal stress vs. shear rate for ultra-high molar mass PMMA, measured by rheo-mechanical devices. Although a similar behaviour can recognise also in some of our plots a hypothesis test is more in favour for a simple linear behaviour. Therefore we cannot confirm this behaviour by rheo-optical technique. Anyway the results show the validity of rheo-optical technique also if the PMMA in solution is not an ideal system for this kind of investigation. In fact the very low optical activity of PMMA in toluene and DMF support to improve the sensitivity of the apparatus, and the use of different kind of cell to avoid the strong flow instabilities observed at high shear rate.

The higher shear rate have been limited by the very strong elastic response of our samples, especially for the high molecular weight samples. This lead to design a new geometry for the cell in the future experiments.

\section{Acknowledgements}

This work was performed as part of a European network financed by the European Commission programmes Human Capital and Mobility of Researches.

The author is grateful to Prof. Bogdan Simionescu who has kindly supplied the PMMA.

The author is grateful to Prof. Dr Ing. Werner Michael Kulicke and all the students of his staff, particularly to Dr Martin Kix, that were close to him with their kindness and friendship during his stage at the Institute of Technical and Macromolecule Chemistry (TMC) Hamburg University. Thanks to everybody.

\section{References}

[1] Bercea M, Peiti C, Simionescu B, Navard P. Macromolecules 1993;26:7095.

[2] Simionescu CI, Iosan S, Simionescu BC. Macromol Chem Macromol Symp 1988;20/21:235.

[3] Cates ME, McLeish TCB, Marrucci GJ. Europhys 1993;L.21:451.

[4] Chinai SN, Matlack JD, Resnick AL, Samuels RJ. J Polym Sci 1955; 17:391.

[5] Chinai SN, Samuels RJ. J Polym Sci 1956;19:463.

[6] Patroni E, Bianchi U. Mack. Chemie 1966:52.

[7] Graessle WW, Penshire HW. J Polym Sci, Part B: Polym Phys 1974;12:2347.

[8] Chen Y, Li J, Hadjichristidis N, Mays J. Polym Bull 1993;30:575.

[9] Jackson C, Chen Y, Mays J. J Appl Polym Sci 1996;61:865.

[10] Shimura Y. Bull Chem Soc Jpn 1967;40:273.

[11] Fox TG. Polymer 1962:111.

[12] Moore WR, Fort RJ. Mack. Chem. 1962:929.

[13] Ginsberg EC, Fox TG, Mason HF. Mack. Chem. 1962:97.

[14] R. dell'Erba, Submitted for publication.

[15] Fuller G. Ann Rev Fluid Mech 1990;22:387. 
[16] Landau, EM. Lifsits, Electrodynamics of continuum media. Editori Riuniti, 1981.

[17] Simionescu BC. J Macromol Sci Chem 1985;A22:765.

[18] Kulicke WM. Proceedings of the 2nd Polymer Symposium, 42, Napa Valley, California, USA Sept. 7-, 1987.

[19] Graessley WW. J Chem Phys 1969;43:2696.

[20] Kulicke WM, Kniewske R. Rheol Acta 1984;23:75.

[21] Kulicke WM, Prescher M. Makromol Chem 1984;185:2619.

[22] Kulicke WM, Porter RS. J Appl Polym Sci 1979;23:953.
[23] Kulicke WM, Kehler H. In: Reichert K-H, Geiseler W, editors. Polymer reaction engineering. Heidelberg: Hüthing, 1986. p. 237.

[24] Kulicke WM, Meyer EL, Fuller G, Clark RC. Macromolecules 1993;26:504.

[25] Kulicke WM, Eidam D, Rinhardt UT, Getreide J. Mehl und Brot 1994;4:56.

[26] E. Pancini, Misure ed apparecchi di fisica. Libreria Eredi Virgilio Veschi, 1965 